ON THE RECORD

\section{"When a 4,700-pound pickup truck meets a 5,000-pound seal, they both lose."}

Ken Cumings of the Friends of the Elephant Seal group in California describes the carnage when the huge beasts try to cross roads.

\section{VALENTINE'S SPECIAL}

\section{A rose by any other hue Blue roses are in production and will} go on sale next year. Developed by Japanese researchers, the genetically modified blooms are likely to be pricey, so start saving.

\section{Kiss and tell \\ Not just an expression of affection: kissing is}

also used subconsciously by both sexes to assess the status of their relationship, say researchers, who say it might also be addictive.

\section{ROBOT NEWS}

\section{Robopump}

Dutch inventors have developed a robot that can pump petrol, removing the tiresome need for drivers to exit their cars at a petrol station. The $€ 75,000$ (US $\$ 109,000)$ automaton finds a match for the vehicle on a database, unscrews the fuel cap and fills the tank.

\section{ZOO NEWS}

\section{Breath of life}

Germany's love of cute baby animals - nicely portrayed by the ongoing Knut shenanigans - has reached a new level. Noticing that a tiger cub had choked on a piece of meat, medical student Janine Bauer climbed into its cage and resuscitated it at Halle Zoo. In gratitude, the zoo has named the tiger after Bauer's son Johann.

Sources: Los Angeles Times, AFP, Scientific American, Spiegel, Reuters

\title{
From Russia with scintillation
}

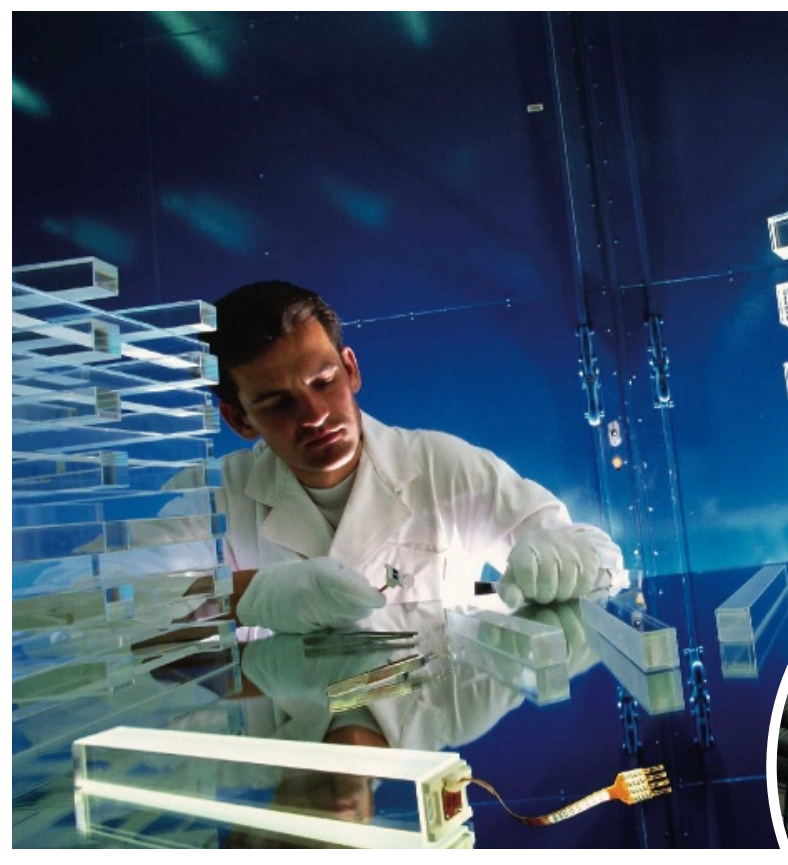

A whopping 76,000 crystals are used in the CERN instrument (inset).

This week, one of the most ambitious and unusual bulk orders in science will finally be filled. At a former Soviet weapons plant in the Russian town of Bogoroditsk, workers will pull from one of their 159 ovens the last of thousands of highly specialized crystals being produced for the Compact Muon Solenoid (CMS). The CMS, a scientific instrument the size of a building, is being assembled at CERN, the European particle-physics laboratory outside Geneva in Switzerland.

\section{"This indeed is the end of a} chapter," says Tejinder Virdee, who leads the CMS group at CERN. It is a chapter that began 14 years ago and is ending in the nick of time - the "When we started,
energy in Russia was
essentially free and
salaries were low."

High-energy particles passing through the calorimeter create showers of secondary particles as they interact with the crystals, and these showers in turn produce light in proportion to the energy of the original particle. "The whole point of the crystal is to convert energy into light," says Philippe Bloch, a physicist at CERN working on the project.

There are various different sorts of crystal that might serve, but in 1994 the CMS team decided that scintillating lead tungstate $\left(\mathrm{PbWO}_{4}\right)$ would best serve their needs. As transparent as glass but nearly four electromagnetic calorimeter for which the crystals have been made must be completed before CERN's Large Hadron Collider (LHC) is switched on in June.

The CMS is one of three detectors that will study the particles given out when the extraordinarily powerful beams of protons provided to the experiment by the LHC smash into each other. The electromagnetic calorimeter's role is to measure the energies of particles coming off the collisions at the detector's centre. times as dense, it allows a compact, radiation-resistant detector that responds quickly to incoming particles. And the showers of secondary particles within it do not spread out too much, making it easier to discriminate between different events.

The problem was that the more energetic the particles produced in a collider, the bigger the detectors need to be. When it is turned on, the LHC will work at higher energies than any previous machine, and the CMS and its fellow 
detectors need to be correspondingly colossal. The electromagnetic calorimeter - one of the smaller components - is 7 metres long and 4 metres across, weighing in at around 100 tonnes. It requires 76,000 crystals - more lead tungstate than all the previous particle detectors in the world combined.

Making the crystals is no easy feat. For starters, each one must sit in a platinum-lined crucible heated to 1,440 kelvin for two-and-a-half days. No factory in Europe was capable of making so many crystals, even with more than a decade's lead-time. So Paul Lecoq, who was in charge of the search for a production site, looked east.
"This was a massive logistical activity. It's not the best way to do it, but it's the only way we could." crystals in Bogoroditsk, around 300 kilometres south of Moscow. The sheer size of the facility stunned him: "It was something I could not have imagined."

Using money set aside for weapons nonproliferation by Western powers, LeCoq and colleagues set about fixing broken ovens and rehiring staff for the factory. The Russian government loaned the collaboration platinum from its reserves, and over the next four years, workers learned how to grow the crystals.

But there were problems. The Russians struggled to obtain the high purities that the CMS requires to obtain accurate data. And Russia itself was changing.

"When we started, energy was essentially free and salaries were low," says Bloch. Towards the end of the 1990s, the cost of labour and energy rose dramatically, and the price tag for the crystals tripled, bringing the cost of the calorimeter to US\$110 million.

Efforts to streamline production floundered,
and to make up for lost time, the team was forced to employ a second factory in China. Even then they struggled to stay on schedule. Indeed, if the start-up date for the LHC itself had not been delayed - it was meant to circulate its first beams in 2007 - it is unlikely that the CMS calorimeter would have been ready in time. As it is, even with the last crystal due out this week, the calorimeter will not quite be finished by its end of May deadline, although it should be good to go soon after. "We are a little bit late, it's true," says Bloch.

Such delays, though, are almost to be expected in a $\$ 480$ million project that seeks to combine bespoke parts from all over the world. The vast steel support structure for the CMS comes from a shipyard in Hudong, China; the pipes in its cooling systems are Polish; its radiation-hardened electronics were built in the United States, France and the United Kingdom. All told, 38 countries have contributed parts to the detector.

"This was a massive logistical activity," says Virdee. "It's not the best way to do it — but it's the only way we could."

Geoff Brumfiel
December 1994, Lecoq found himself inside a once secret underground plant for growing
Efforts to streamline production floundered,
and to make up for lost time, the team was
SHIP KITES INTO PORT
After the maiden vogage of the SkySails cargo ship, Nature News examines towing ships with kites. www.nature.com/news masse for their radars and missile guidance systems. "They have grown everything you can dream of, Lecoq says. And the form Soviet Union built production facilities on 